\title{
Granulocyte Colony-Stimulating Factor and Granulocyte-Macrophage Colony-Stimulating Factor Have Differential Effects on Neonatal and Adult Neutrophil Survival and Function
}

\author{
ELEANOR J. MOLLOY, AMANDA J. O'NEILL, JULIE J. GRANTHAM, \\ MARGARET SHERIDAN-PEREIRA, JOHN M. FITZPATRICK, DAVID W. WEBB, AND \\ R. WILLIAM G. WATSON \\ Department of Surgery, Mater Misericordiae University Hospital, Dublin 7, and Conway Institute of \\ Biomolecular and Biomedical Research [E.J.M., A.J.O., J.M.F., R.W.G.W.], Dublin 4, Ireland; \\ Department of Paediatrics [E.J.M., J.J.G., M.S.-P.], Coombe Women's Hospital, Dublin 6, Ireland; and \\ Department of Neurology [D.W.W.], Our Lady's Hospital for Sick Children, Dublin 12, University College
}

Dublin, Dublin 4, Ireland

\begin{abstract}
Neutropenia is a common sequela of neonatal sepsis. Recent clinical trials have shown the beneficial effects of colonystimulating factors (CSFs) on outcome in this group, but the exact mechanism remains unknown. Neonates and mothers who were at high-risk for infection were recruited for cord blood sampling in a university tertiary referral maternity hospital. Neonatal and adult neutrophils were evaluated for their ability to combat bacterial infection by examining their functional activity (CD11b and reactive oxygen intermediates) and their persistence at inflammatory sites (apoptosis). The mechanism for altered apoptotic responses was assessed by caspase activation assays, $\mathrm{X}$ chromosome-linked inhibitor of apoptosis protein expression, and cytosolic cytochrome $c$ release. Although granulocyte colony-stimulating factor (G-CSF) and granulocyte-macrophage colony-stimulating factor (GM-CSF) significantly delayed neutrophil apoptosis in normal adults, only G-CSF had a similar effect in normal neonates. Neutrophils from neonates who are at high risk for infection are unresponsive to the antiapoptotic effects of G-CSF or GM-CSF, unlike maternal neutrophils, which have delayed apoptosis in response to GM-CSF. However, CD11b expression and reactive oxygen intermediate production were significantly increased in normal neonatal neutrophils that were incubated with GM-CSF versus controls but not G-CSF or
\end{abstract}

\section{ABSTRACT}

lipopolysaccharide. Decreased cytosolic cytochrome $c$ release and caspases 3 and 9 activity are associated with the CSFmediated delay in apoptosis in adults but not in newborns. The antiapoptotic X chromosome-linked inhibitor of apoptosis protein is up-regulated in neonates compared with adults and may mediate their differential spontaneous apoptosis. These results have important implications for the use of CSFs in neonatal sepsis, as responses differ from those seen in adults. Further delineation of neonatal neutrophil responses to CSFs may improve their therapeutic potential. (Pediatr Res 57: 806-812, 2005)
DHR, Dihydrorhodamine ${ }^{123}$
Abbreviations
G-CSF, granulocyte colony-stimulating factor
GM-CSF, granulocyte-macrophage colony-stimulating factor
IAP, inhibitor of apoptosis protein
LPS, lipopolysaccharide
MnSOD, manganese sodium dismutase
PMA, phorbol 12-myristate 13-acetate
ROI, reactive oxygen intermediates
VD, vaginal delivery
XIAP, X chromosome-linked inhibitor of apoptosis protein

The toll of neonatal sepsis remains high despite continuing advances in neonatal intensive care and improved strategies to

Received April 20, 2004; accepted September 27, 2004

Correspondence: Eleanor Molloy, M.D., Ph.D. Department of Neonatology, Rainbow Babies and Children's Hospital, 11100 Euclid Avenue, Cleveland, OH 44106; e-mail: elesean@hotmail.com.

Supported by grants from the Health Research Board of Ireland (Clinical Research Fellowship, E.J.M.); the Mater College, Ireland; and the Children's Research Fund, Our Lady's Hospital for Sick Children, Ireland.

DOI: 10.1203/01.PDR.0000156500.13600.B5 combat infection. This has been attributed to several factors, including the survival of more premature neonates. Neonates are particularly vulnerable to Gram-negative organisms as a result of altered neutrophil function at birth and their susceptibility to neutropenia in response to sepsis $(1,2)$. This reduced bactericidal capacity coupled with the growing public health threat of antibiotic resistance (3) has prompted the exploration of alternative therapies for sepsis, such as the colonystimulating factors (CSFs). 
Granulocyte colony-stimulating factor (G-CSF) and granulocyte-macrophage colony-stimulating factor (GM-CSF) have been proposed as adjunctive treatments for neonatal sepsis to ameliorate neutropenia. G-CSF and GM-CSF promote the release of neutrophil progenitors from the bone marrow and increase neutrophil survival in the circulation (4), potentially increasing the circulating neutrophil pool to better combat sepsis. However, despite multiple clinical trials of these agents in neonatal sepsis, they are not in routine usage (5-7). Prophylactic GM-CSF in preterm infants with sepsis has been more successful $(8,9)$ but is not standard therapy either.

In adults, G-CSF improved outcome in septic shock (10). However, G-CSF and GM-CSF have been shown to increase both reactive oxygen intermediate (ROI) production and CD11b expression during sepsis (11). In addition, G-CSF- and GM-CSF-related pulmonary toxicity has been reported in rats and is associated with potentiation of proinflammatory cytokine production (12). Therefore, more extensive trials are required before these agents come into routine usage for adult or neonatal sepsis.

Regulation of neutrophil apoptosis is vital to maintain sufficient neutrophils at an inflammatory site to fight infection balanced against the risk for excessive neutrophil activation inducing tissue damage (13). Neonatal neutrophils have altered inflammatory responses compared with adults. We therefore aimed to explore the effect of G-CSF and GM-CSF on neonatal neutrophil function and survival in both normal mothers and neonates and those at high risk for sepsis. We also investigated the prosurvival mechanism by which G-CSF and GM-CSF delay neutrophil apoptosis.

\section{METHODS}

Reagents and antibodies. The following reagents and antibodies were used: Dulbecco's modified Eagle medium, penicillin, streptomycin solution, Lglutamine, and FCS (GIBCO Life Technologies Ltd., Paisley, UK); Dextran T-500 and Ficoll (Pharmacia, Buckinghamshire, UK); E-lyse (Cardinal Associates, Santa Fe, NM); Dihydrorhodamine ${ }^{123}$ (DHR; Molecular Probes, Eugene, OR); phorbol 12-myristate 13-acetate (PMA; Sigma Chemical Co., St. Louis, MO); CD11b (LeuTM-15) PE (Becton Dickinson, San Hose, CA); anti-cytochrome $c$ antibody (Pharmingen, Oxford, UK, and also a gift from Dr. Seamus Martin, Trinity College, Dublin, Ireland); rabbit anti-manganese superoxide dismutase (MnSOD) polyclonal antibody (Stressgen, Victoria, BC, Canada); G-CSF and GM-CSF (R\&D Systems, Minneapolis, MN); TRIzol (GibcoBRL Life Technologies Grand Island, NY); DNase I (Invitrogen, Life Technologies, Paisley, UK); RNeasy Mini Kit (Qiagen, West Sussex, UK); Random primers, dNTPs, and Superscript II RNase $\mathrm{H}^{-}$Reverse Transcriptase (Invitrogen, Life Technologies); and Taqman Universal PCR Master Mix Kit (Applied Biosystems, Foster City, CA). All remaining chemicals were purchased from Sigma Chemical Co.-Aldrich (Dorset, UK) unless otherwise stated.

Patient groups. Healthy volunteers from laboratory staff with an equal ratio of men and women donated whole-blood samples. Umbilical cord blood was taken after normal, uncomplicated vaginal deliveries (VDs) with fully informed consent, and neutrophil isolation was commenced within $90 \mathrm{~min}$.

Ethical Committee approval was received from the Coombe Women's Hospital for the study period from July 1, 2000, to June 30, 2003. Informed consent was granted and study proformas were completed (J.G.) on all patients. The following patient groups were used:

1. Adults: Healthy adult men and nonpregnant women aged 26-33 y.

2. Neonatal: $a$ ) Normal labor (VD): umbilical cord blood samples taken at term after normal pregnancy, labor, and delivery. All infants had an uncomplicated postnatal course and were age- and sex-matched with Apgar scores of $>5$ at 5 min. $b$ ) High-risk sepsis: infants who were at high risk for infection were included using the following criteria (14): $i)$ maternal fever $\left(>38^{\circ} \mathrm{C}\right)$ with or without fetal tachycardia; ii) prolonged rupture of membranes ( $>24 \mathrm{~h})$; iii) chorioamnionitis (15); and iv) maternal Group B Streptococcal (GBS) infection (positive culture and/or GBS urinary tract infection). Infants with major congenital abnormalities were excluded. Retrospectively, the infants were divided into subgroups as follows: $a$ ) high-risk sepsis with normal outcome (HR sepsis) and asymptomatic (no clinical signs of infection and a negative blood culture) and $b$ ) clinical or microbiological evidence of sepsis (sepsis) with negative cultures, abnormal white blood cell count, or strong and persistent clinical signs of infection.

3. Maternal: a) Normal labor (VD): healthy women in labor at term before delivery and $b$ ) HR sepsis women with antepartum signs of infection.

Preparation of cells. Neutrophils were isolated by dextran (3\%) sedimentation and centrifugation through a discontinuous Ficoll gradient. Red blood cells were lysed using E-Lyse (16). The neutrophil pellet was resuspended in Dulbecco's modified Eagle medium culture medium supplemented with $10 \%$ FCS, $1 \%$ glutamine, $1 \%$ penicillin/streptomycin solution, and Fungizone at a concentration of $1 \times 10^{6}$ cells $/ \mathrm{mL}$. Cells were incubated in polypropylene tubes (Falcon/Becton Dickinson, Cambridge, UK) to prevent adherence. Neutrophil purity as assessed by size, and granularity on flow cytometry was consistently $>95 \%$. Neutrophils at $1 \times 10^{6}$ cells $/ \mathrm{mL}$ were treated with 1 $\mu \mathrm{g} / \mathrm{mL}$ lipopolysaccharide (LPS), $8 \mathrm{ng} / \mathrm{mL}$ G-CSF, and $8 \mathrm{ng} / \mathrm{mL}$ GM-CSF, where indicated.

Quantification of apoptosis. Spontaneous apoptosis of neutrophils was quantified by flow cytometry as the percentage of cells with hypodiploid DNA (16). Cells $\left(1 \times 10^{6} / \mathrm{mL}\right)$ were centrifuged at $130 \times g$ for $5 \mathrm{~min}$ and then gently resuspended in $400 \mu \mathrm{L}$ of hypotonic fluorochrome solution $(200 \mathrm{~mL}$ of PBS, $10 \mathrm{mg}$ of propidium iodide, $3.4 \mathrm{mM}$ sodium citrate, $1 \mathrm{mM}$ Tris, $0.1 \mathrm{mM}$ EDTA, and $0.1 \%$ Triton X-100). They were placed on ice for 10 min before they were analyzed using the Coulter Epics XL-MCL cytofluorometer (Miami, FL). A minimum of 5000 events were collected and analyzed. Apoptotic nuclei were distinguished from normal nuclei by their hypodiploid DNA, and debris was excluded from analysis by raising the forward threshold. All measurements were performed under the same instrument settings. Apoptosis was also confirmed by Annexin V binding, according to the manufacturer's guidelines (R\&D Systems).

Quantification of cell-surface antigen expression. The expression of $\mathrm{CD} 11 \mathrm{~b}$ antigen on the surface of neutrophils was measured by flow cytometry. Cells $\left(1 \times 10^{6} / \mathrm{mL}\right)$ were treated with PE-CD11b or control antibody and left at $4^{\circ} \mathrm{C}$ for $20 \mathrm{~min}$. Cells were washed three times with $400 \mu \mathrm{L}$ of cold PBS at $130 \times g$ for $10 \mathrm{~min}$ and finally resuspended in $400 \mu \mathrm{L}$ of Isoton II solution and stored on ice before they were analyzed by flow cytometry and expressed as mean channel fluorescence.

Western blot analysis. Isolated neutrophils were prepared for cytochrome $c$ evaluation by initially pelleting the cells followed by resuspension in $100 \mu \mathrm{L}$ of CLAMI Buffer (250 mM sucrose and $70 \mathrm{mM} \mathrm{KCL}$ in PBS) that contained $200 \mu \mathrm{g} / \mathrm{mL}$ digitonin. After a 5-min incubation on ice, the cells were pelleted at $1000 \times g$ for $5 \mathrm{~min}$ at $4^{\circ} \mathrm{C}$. The supernatant or cytosolic fraction was stored at $-70^{\circ} \mathrm{C}$ until $30 \mu \mathrm{L}$ was run on Western blot. The pellet that contained the mitochondrial fraction was resuspended in $100 \mu \mathrm{L}$ of Universal Immunoprecipitation Buffer [50 mM Tris- $\mathrm{HCl}$ (pH 7.4), $150 \mathrm{mM} \mathrm{NaCl}, 2$ mM EDTA, 2 mM EGTA, $0.2 \%$ Triton X-100, 0.3\% NP-40, 1 mM PMSF, leupeptin, and aprotinin) for $10 \mathrm{~min}$ on ice. The solution then was pelleted at $10,000 \times g$ for $10 \mathrm{~min}$ at $4^{\circ} \mathrm{C}$, and the supernatant or mitochondrial fraction was stored at $-70^{\circ} \mathrm{C}$ until $30 \mu \mathrm{L}$ was run on a Western blot. Anti-cytochrome $c$ antibody $(1: 1000)$ was the primary antibody, and the secondary antibody used was horseradish peroxidase-conjugated anti-rabbit $\operatorname{IgG}$ at 1:5000 dilution for $1 \mathrm{~h}$.

MnSOD is used as a specific marker of the mitochondrial fraction of the cell lysate (17). MnSOD antibody was used to confirm the purity of the cytosolic and mitochondrial fractions. Blots were incubated with the antibody at 1:1000, and the secondary antibody used was horseradish peroxidase-conjugated anti-rabbit IgG at 1:5000 dilution for $1 \mathrm{~h}$.

Blots were developed using the enhanced chemiluminescence system. The density of each band was measured using the UN-SCAN-IT gel Version 5.1 program.

Respiratory burst activity (ROI). Generation of ROI was evaluated by flow cytometry (18). Neutrophils $\left(500 \mu \mathrm{L} ; 1 \times 10^{6} / \mathrm{mL}\right)$ were incubated with DHR $(100 \mu \mathrm{M})$ at $37^{\circ} \mathrm{C}$ for $10 \mathrm{~min}$ before stimulation with $1 \mu \mathrm{L}(16 \mu \mathrm{M})$ of PMA for $20 \mathrm{~min}$ at $37^{\circ} \mathrm{C}$. The reaction then was halted by placing samples on ice. Neutrophil fluorescence intensity was assessed by flow cytometry and expressed as Ln mean channel fluorescence. DHR has been shown to detect mainly intracellular $\mathrm{H}_{2} \mathrm{O}_{2}$ and $\mathrm{OH}$ radical production (18).

Caspase extraction and activity assay. Cell lysates were prepared from 10 $\times 10^{6}$ cells using caspase isolation buffer [25 mM HEPES (pH 7.8), $5 \mathrm{mM}$ $\mathrm{MgCl}_{2}, 1 \mathrm{mM}$ EDTA, $10 \mathrm{mM}$ leupeptin, $5 \mathrm{mM}$ pepstatin, $100 \mathrm{mM}$ PMSF, and $10 \mathrm{mM}$ dithiothreitol] and caspase incubation buffer [100 mM HEPES (pH 7.5), $10 \%$ sucrose, $0.1 \%$ CHAPS, $10 \mathrm{mM}$ leupeptin, $5 \mathrm{mM}$ pepstatin, $100 \mathrm{mM}$ PMSF, and $10 \mathrm{mM}$ dithiothreitol]. Aliquots of the lysates $(40 \mu \mathrm{L})$ were diluted in caspase incubation buffer $(40 \mu \mathrm{L})$ and $20 \mathrm{mM}(5 \mu \mathrm{L})$ Ac-LEHD-AMC (caspase 9) or $20 \mathrm{mM}$ Ac-DEVD-AMC (caspase 3) and incubated for $1 \mathrm{~h} \mathrm{at}$ 
$37^{\circ} \mathrm{C}$ in a 96-well co-star plate. The release of AMC fluorescent tag was measured using a cytofluorometer II (Perkin Elmer Biosciences, Birchwood Science, Park North, Warrington, UK) at $380 \mathrm{~nm}$ excitation and $460 \mathrm{~nm}$ emission. The difference between specific caspase activity at 0 and $1 \mathrm{~h}$ was calculated and expressed as caspase activity per microgram of protein.

Real-time PCR. The inhibitor of apoptosis proteins (IAPs) have been implicated in delayed neutrophil apoptosis, both spontaneous and G-CSF induced (19-22). We used the Primer Express version 1 from Applied Biosystems to design the primer and probe. The amplicon size expected for $\mathrm{X}$ chromosome-linked IAP (XIAP) is $93 \mathrm{bp}$. The controls used were 18S and real-time controls.

cDNA synthesis. Total cellular RNA was isolated from neutrophils using TRIzol. Total RNA then was cleaned further with the RNeasy Mini Kit. RNA was treated with DNase I to digest single- and double-stranded DNA before cDNA preparation. To generate cDNA, we used $1 \mu \mathrm{g}$ of RNA for each reaction and random primers dNTPs and Superscript II RNase $\mathrm{H}^{-}$Reverse Transcriptase. The reaction mixtures were incubated at $25^{\circ} \mathrm{C}$ for $10 \mathrm{~min}$ (primers), $42^{\circ} \mathrm{C}$ for $50 \mathrm{~min}$ (reverse transcription), and $70^{\circ} \mathrm{C}$ for $15 \mathrm{~min}$ (enzyme inactivation).

Real-time PCR. The Taqman Universal PCR Master Mix Kit is optimized for TaqMan reactions and contains AmpliTaq Gold DNA Polymerase, AmpErase UNG, dNTPs with dUTP, Passive Reference Dye (ROX), and optimized buffer components. The following primer pairs were used. For each set, the forward and reverse primers and the accession number are listed: XIAP forward 5'-GGA ACC TTG TGA TCG TGC CT-3', XIAP reverse 5'-AAG ATT CCG GCC CAA AAC A-3', XIAP probe 5'-CAG AAC ACA GGC GAC ACT TTC CTA ATT GCT-3'.

The default thermal conditions for the PCR amplification were as follows: $2 \mathrm{~min}$ at $50^{\circ} \mathrm{C}$ to activate AmpErase UNG, $10 \mathrm{~min}$ at $95^{\circ} \mathrm{C}$ to activate AmpliTaq Gold Enzyme, $15 \mathrm{~s}$ at $95^{\circ} \mathrm{C}$ to denature DNA, and $1 \mathrm{~min}$ at $60^{\circ} \mathrm{C}$ to anneal and extend template. The denaturation and extension steps were run for 40 cycles after the initial enzyme activation steps.

Statistics. Statistical analysis was carried out using one-way ANOVA with Student-Newman correction and $t$ test using Minitab statistical software 13.32 (www.minitab.com). Significance was assumed for values of $p<0.05$. Results are expressed as mean \pm SD unless otherwise indicated.

\section{RESULTS}

Patient demographics. There were no significant differences in sex ratio [VD, 55\% male; HR sepsis, 50\% male], gestation [VD, 40.1 (1.3); HR sepsis, 36.9 (6.4)], or labor length [VD, $5.0(0.1)$; HR sepsis, $6.4(0.2)$ ] between the groups. However, the HR sepsis group had significantly lower birth weights [VD, 3.6 (0.6); HR sepsis, 3.1 (1.2)] and Apgar scores at 1 min [VD, 9.0 (0.5); HR sepsis, 7.4 (2.6)].

Delayed neutrophil apoptosis in response to G-CSF and $\boldsymbol{G M}$ - CSF . Normal neonatal neutrophil apoptosis after VD was significantly delayed compared with adults (23). Although G-CSF and GM-CSF significantly delayed neutrophil apoptosis in normal adults, only G-CSF had a similar significant $(p=0.02)$ effect in neonates. Both adult and neonatal neutrophils demonstrate a significant delay in apoptosis in response to LPS, although neonatal neutrophils are not as responsive as adults. Because neonatal neutrophils already have delayed apoptosis compared with adults, their responses to CSFs seem decreased, although apoptotic rates after CSFs are similar in both groups. Priming neutrophils from both adults and newborns with LPS, before the addition of G-CSF, significantly enhanced the delay in apoptosis compared with LPS alone. However, in both adults and newborns, LPSinduced delayed apoptosis was not significantly altered by the addition of GM-CSF (Fig. 1).

Neutrophils that were derived from mothers responded to G-CSF and GM-CSF in all groups (Fig. 2A). In contrast, neonates who were at high risk for sepsis showed no significant delay in apoptosis with G-CSF, although they responded to the combination of G-CSF and LPS (Fig. 2B). GM-CSF did not further delay neutrophil apoptosis in neonatal HR sepsis.
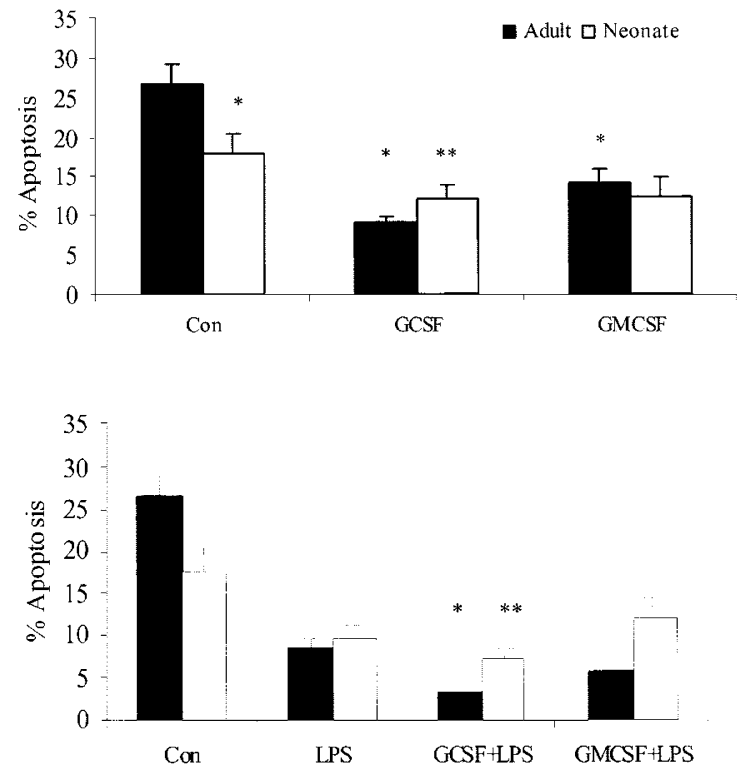

Figure 1. Effects of G-CSF and GM-CSF on neutrophil apoptosis in normal neonates and adults in vitro. Neutrophils $\left(1 \times 10^{6}\right.$ cells $\left./ \mathrm{mL}\right)$ were isolated from healthy adult control subjects $(n=20)$ and umbilical cord blood from normal newborns after spontaneous uncomplicated VD (Neo norm; $n=20)$. Cells were incubated in vitro with G-CSF $(8 \mathrm{ng} / \mathrm{mL})$ and GM-CSF $(8 \mathrm{ng} / \mathrm{mL})$ or alone for $24 \mathrm{~h}$ or with LPS ( $1 \mu \mathrm{g} / \mathrm{mL})$ for $1 \mathrm{~h}$ before G-CSF and GM-CSF. $(A)$ $* p<0.05 v s$ adult control; ** $p<0.05$ vs neonatal control. $(B) * p<0.05$ vs LPS alone adult; $* * p<0.05$ vs LPS alone neonate.

Neutrophil function increased by G-CSF and GM-CSF. $\mathrm{CD} 11 \mathrm{~b}$ is a marker of neutrophil adhesion and antibacterial function. It is up-regulated in adults in response to G-CSF and GM-CSF. Neonatal neutrophils showed increased surface expression of CD11b in response to LPS and GM-CSF but not after incubation with G-CSF. The ability of G-CSF and GMCSF to prime for an additive response to LPS was also investigated. These cytokines did not increase the ability of LPS to stimulate CD11b expression (Fig. 3A). LPS or LPS and GM-CSF markedly increased neonatal ROI production after PMA stimulation. However, neither G-CSF nor GM-CSF alone increased neonatal ROI production (Fig. $3 B$ ). There was no additive response to LPS and CSFs, and there may even be an inhibitory response, although this is not statistically significant.

Caspases 3 and 9 activity is decreased in adults with CSFs. To examine the mechanism of delayed neonatal neutrophil apoptosis, we initially examined the spontaneous activation of caspases 3 and 9. Previous studies have shown spontaneous activity of caspases 3 and 9 in adult neutrophils, which are activated by the release of cytochrome $c$ from the mitochondria (24). Previously, we found the optimal caspase activity to occur at $18 \mathrm{~h}$ (16). Adults have higher caspases 3 and 9 activity than newborns at both 0 and $18 \mathrm{~h}$. This mirrors the differences in apoptosis between these groups. In adults, caspases 3 and 9 activities were significantly diminished by LPS, G-CSF, and GM-CSF (Fig. 4). In contrast, neonates had decreased caspases 3 and 9 activity only after GM-CSF. However, the levels reached are equivalent to those of adults who are treated with G-CSF and GM-CSF.

Spontaneous cytochrome c release from the mitochondrion and mitochondrial stability in response to G-CSF and GM$\boldsymbol{C S F}$. Cytochrome $c$ release from the mitochondrion into the 
(a)

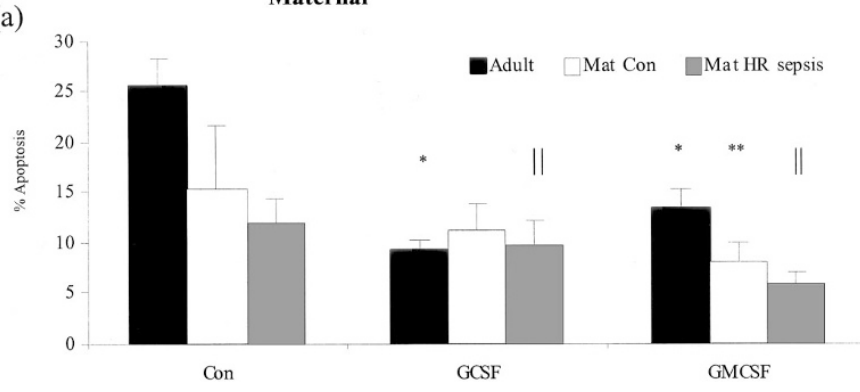

(b)

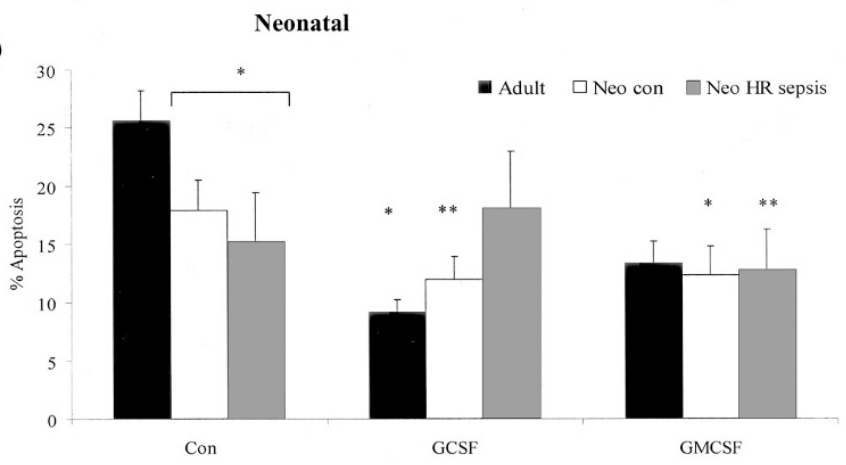

Figure 2. Apoptotic responses to G-CSF and GM-CSF in maternal neutrophils with risk factors for sepsis $(A)$ and newborns at high risk for sepsis $(B)$. Neutrophils $\left(1 \times 10^{6}\right.$ cells $\left./ \mathrm{mL}\right)$ were isolated from healthy adult control subjects $(n=20)$, umbilical cord blood from normal newborns after spontaneous uncomplicated VD (Neo norm; $n=20$ ), and mothers with risk factors for sepsis (HR sepsis; $n=23$; $A$ ) and neonates at high risk for infection (HR sepsis; $n=20 ; B$ ). Cells were incubated in vitro with G-CSF $(8 \mathrm{ng} / \mathrm{mL})$ and GM-CSF $(8 \mathrm{ng} / \mathrm{mL})$ or alone for $24 \mathrm{~h}$ or with LPS $(1 \mu \mathrm{g} / \mathrm{mL})$ for $1 \mathrm{~h}$ before G-CSF and GM-CSF. $(A) * p<0.05$ $v s$ adult control; **p $<0.05 v s$ maternal control; $\| v s$ mat HR sepsis control. $(B)$ ${ }^{*} p<0.05$ vs adult control; ** $p<0.05$ vs neonate control

cytosol is central to the formation of the apoptosome and the activation of the caspases that lead to apoptosis (24). In adult neutrophils, there is virtually no cytochrome $c$ in the cytosol at time $0 \mathrm{~h}$, but, as the neutrophil ages, this protein is released from the mitochondrion. Previously, we found the maximal cytosolic release to occur at $18 \mathrm{~h}$ (25). Co-incubation with LPS, G-CSF, and GM-CSF significantly inhibits cytochrome $c$ release into the cytosol in adults but not in newborns (Fig. 5). MnSOD confirmed pure cytosolic fractions (Fig. 5).

IAPs increased in newborns. XIAP mRNA is elevated in neonatal neutrophils compared with adults (Fig. 6A). However, there were no significant differences in XIAP protein expression between neonates and adults (Fig. 6B).

\section{DISCUSSION}

Neonates have altered neutrophil function and survival compared with adult control subjects, which affects their ability to mount an adequate inflammatory response to potentially combat a septic or sterile insult. We have demonstrated that G-CSF increases neonatal neutrophil survival by delaying apoptosis but does not seem to significantly alter neutrophil function. In contrast, in neonatal neutrophils, GM-CSF does not significantly delay apoptosis but does enhance function. The differential effects of these cytokines on neutrophil apoptosis in adults compared with newborns (after elective cesarean sec-
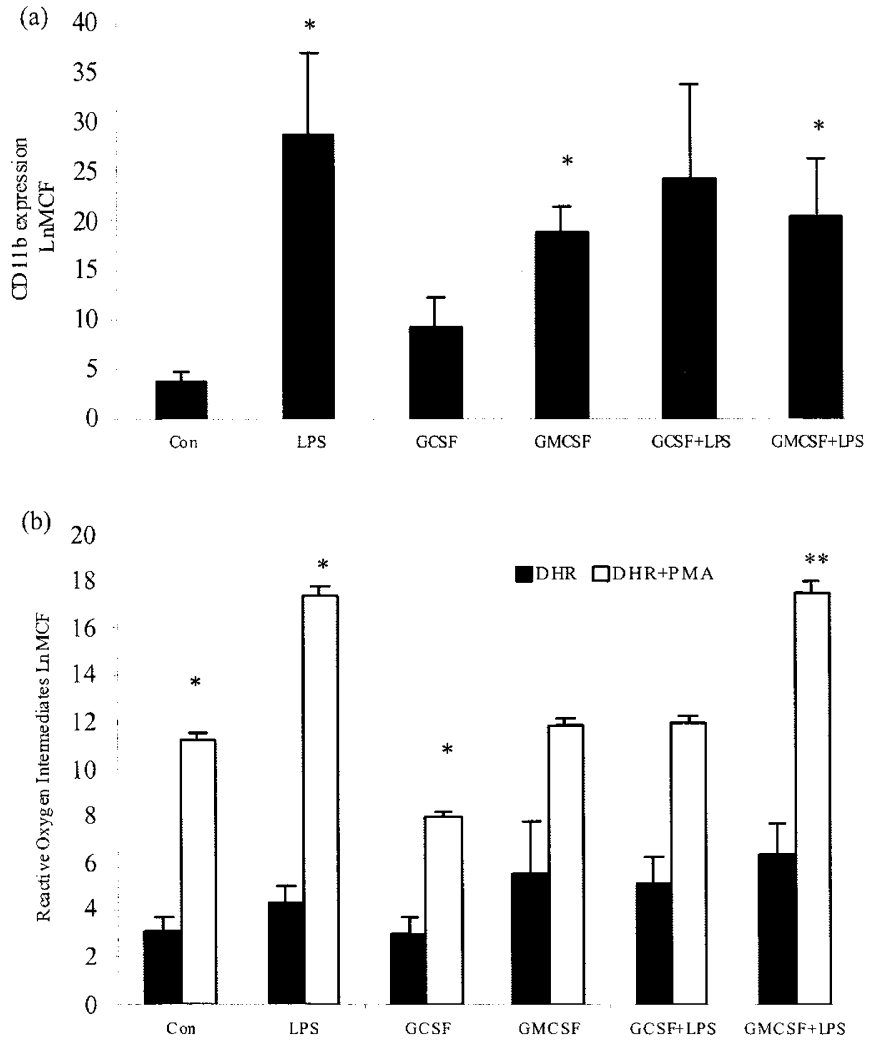

Figure 3. The effect of G-CSF and GM-CSF on CD11b expression $(A)$ on the neonatal neutrophil and ROI production $(B)$ in response to G-CSF and GMCSF in neonatal neutrophils after LPS priming. Normal neutrophils $\left(1 \times 10^{6}\right.$ cells $/ \mathrm{mL}$ ) were also incubated for $1 \mathrm{~h}$ either with or without G-CSF or GM-CSF (both $8 \mathrm{ng} / \mathrm{mL}$ ) before the addition of LPS ( $1 \mu \mathrm{g} / \mathrm{mL} ; n=4)$. (B) ROI activity was assessed in neutrophils that were preincubated with G-CSF or GM-CSF for $6 \mathrm{~h}$ and then stimulated with PMA $(5 \mathrm{nM})$ for $10 \mathrm{~min}$. Neutrophils were also preincubated with LPS $(1 \mu \mathrm{g} / \mathrm{mL})$ for $1 \mathrm{~h}$ before the addition of G-CSF/GM-CSF. Results were expressed as the Ln mean channel fluorescence $\pm \mathrm{SD}(n=4)$. (A) $* p<0.05$ vs control. $(B) * p<0.05$ vs control DHR; ** $p$ $<0.05$ vs GM-CSF + PMA.

tions) were observed previously (26), but the current study extends this observation to normal neonates after normal VD.

Previous research has revealed that preterm and septic neonates have diminished ROI and CD11b responses when compared with control subjects (27). In neonatal sepsis, neutrophils have a more immature phenotype with diminished functional activation (1). Neonates rapidly deplete their small neutrophil pool when septic, resulting in neutropenia (28). This may indicate a compensatory anti-inflammatory response syndrome in the neonate, which is at variance with the predominant adult systemic inflammatory response syndrome in sepsis. The immunosuppression and neutropenia that characterize neonatal sepsis would be in accordance with this theory. Neonatal neutrophils are relatively hyporesponsive to G-CSF and GMCSF when compared with adult cells, especially in infants with maternal risk factors for sepsis irrespective of outcome. However, CSF responses reach similar final functional and apoptotic levels in both adults and neonates. Because neutrophil apoptosis is delayed in neonates, there is an apparent hyporesponsiveness to many stimuli. G-CSF enhances neonatal neutrophil survival with no significant impact on neutrophil func- 
(a)

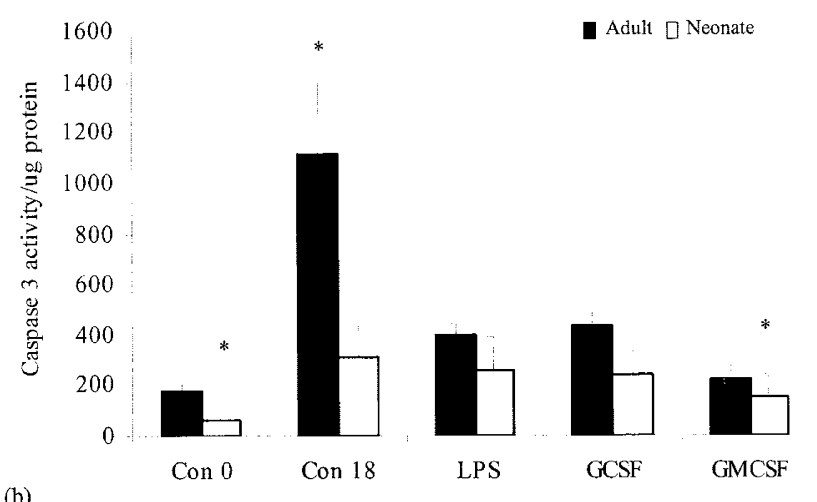

(b)

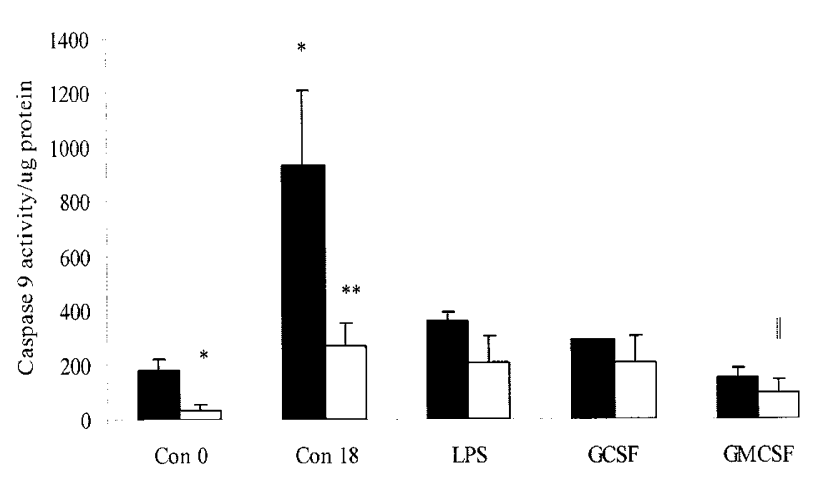

Figure 4. Spontaneous caspase $3(A)$ and $9(B)$ activation by LPS, G-CSF, and GM-CSF using fluorescent caspase substrates in adults and neonates. Normal neutrophils $\left(1 \times 10^{6}\right.$ cells $\left./ \mathrm{mL}\right)$ were incubated for $18 \mathrm{~h}$ with LPS $(1$ $\mu \mathrm{g} / \mathrm{mL}), \mathrm{G}-\mathrm{CSF}$ ( $8 \mathrm{ng} / \mathrm{mL})$, or GM-CSF $(8 \mathrm{ng} / \mathrm{mL})$. Cell lysates were prepared from $10 \times 10^{6}$ neutrophils using caspase isolation and incubation buffers at 0 and $18 \mathrm{~h}$ in controls (con 0 and con 18) and $18 \mathrm{~h}$ in LPS-, G-CSF-, or GM-CSF-treated cells. Each graph represents at least three separate experiments performed in duplicate (mean \pm SEM). $(A) * p<0.05 v s$ control $0 \mathrm{~h}$ adult; ${ }^{* *} p<0.05$ vs control cord $0 \mathrm{~h} ; \| p<0.05 v s$ control $18 \mathrm{~h}$. (B) *p $<0.05$ $v s$ control $0 \mathrm{~h}$ adult; ** $p<0.05$ vs control cord $0 \mathrm{~h} ; \| p<0.05$ vs control $18 \mathrm{~h}$.

tion (CD11b, ROI). In contrast, after LPS priming, GM-CSF significantly increased neutrophil respiratory burst and CD11b expression.

GM-CSF and G-CSF stimulate increased neonatal neutrophil chemotaxis, enhance CD11b expression, and decrease L-selectin expression $(29,30)$. GM-CSF primes for PMAinduced respiratory burst to the same extent in term neonates, preterm neonates in intensive care, and adults in whole blood (a)

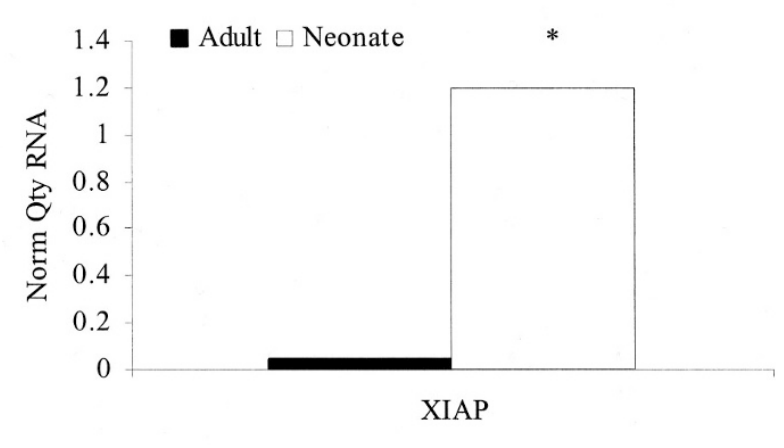

(b)

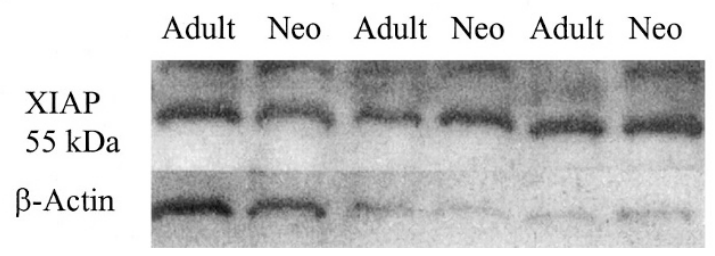

Figure 6. XIAP in adults and neonates. (A) Real-time PCR. ( $B$ and $C$ ) Western blot. Normal neutrophils $\left(1 \times 10^{6} \mathrm{cells} / \mathrm{mL}\right)$ from adults and neonates were isolated at $0 \mathrm{~h}$. Real-time PCR was used to examine the fold increase in XIAP $(A)$ in RNA from adults and neonates. $(B)$ Western blotting was also used. These blots represent six adults and six neonates. ${ }^{*} p<0.05 v s$ adult control.

and to a greater degree than G-CSF in neonatal neutrophils (31). These in vitro effects of G-CSF and GM-CSF on neutrophil function studies have been confirmed in vivo in septic infants $(32,33)$ and in children with cancer (34). In septic neutropenic preterm infants, although G-CSF increases neutrophil phagocytic capacity and oxidative capacity, levels do not reach those of normal preterm control infants (33).

G-CSF receptors are reduced on neonatal neutrophils compared with adults (35), which may explain the lack of enhanced functional activity. Moreover, G-CSF receptor expression is down-regulated in neonatal sepsis (35) and may explain decreased responses of neutrophils found in infants who are at high risk for infection. Decreased stimulated GM-CSF production and GM-CSF gene expression but normal numbers of GM-CSF receptors have been found on mononuclear cells from human term newborns compared with adults (36). Serum G-CSF and GM-CSF levels are also elevated in neonatal sepsis
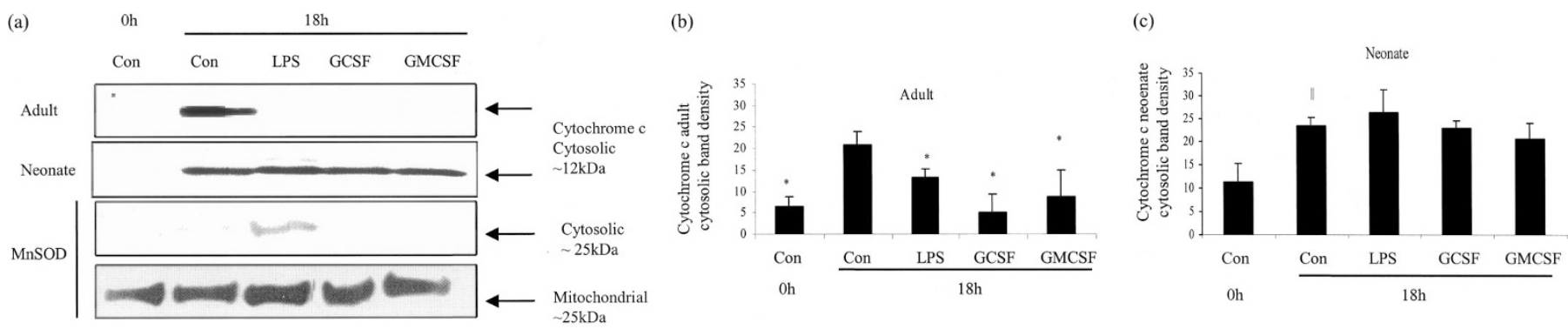

Figure 5. The effects of G-CSF and GM-CSF on spontaneous cytochrome $c$ release: Western blot, MnSOD in cytosolic and mitochondrial fractions, and densitometry. Cytoplasmic fractions were also extracted at $18 \mathrm{~h}$ from control neutrophils and cells that were incubated with LPS (1 $\mu \mathrm{g} / \mathrm{mL}), \mathrm{G}-\mathrm{CSF}$ ( $8 \mathrm{ng} / \mathrm{mL}$ ), and GM-CSF $(8 \mathrm{ng} / \mathrm{mL})$ in adults and cords. Each blot represents one of three separate experiments. Densitometry was performed, and density of each band (percentage of total pixels) is expressed as the mean $\pm \mathrm{SD}$ of all blots. $* p<0.05 v s$ adult con $18 \mathrm{~h} ; * p<0.05 v s$ neonate control $0 \mathrm{~h}$. 
and with increasing gestational age $(37,38)$. This may suggest that neutrophil functional activity may be mediated by the respective receptor ligation, and apoptosis may be delayed via a cytokine receptor-independent mechanism.

The exact mechanisms that mediate the prosurvival effects of CSFs are unclear. G-CSF seems to mediate its prosurvival effect in the neutrophil via the mitochondrial apoptotic pathway by preventing Bax translocation, cytochrome $c$ release, and subsequent caspase 3 activation $(21,39,40)$. We have confirmed that G-CSF and GM-CSF inhibit cytochrome $c$ release and caspase activity in adult neutrophils. LPS, G-CSF, or GM-CSF had no ability to prevent spontaneous release of cytochrome $c$ from neonate neutrophil; however, there was a significant reduction in caspases 3 and 9 activity compared with adults. In an attempt to identify why there is a basal resistance to apoptosis in neonate neutrophils at the level of caspase activity, we investigated the expression of the IAPs between the two cell populations. Despite the significantly greater levels of XIAP mRNA in neonatal than adult neutrophils, we could not detect any significant difference in protein expression. This may rule out a role for the XIAP in this delay. Other IAPs, including cIAP-2, have been associated with delayed apoptosis and are up-regulated by G-CSF and may be important in this mechanism (22).

In determining the differential effects of G-CSF and GMCSF, we showed that G-CSF has a greater prosurvival effect in neonatal neutrophils than GM-CSF, even after LPS priming. However, GM-CSF augments neonatal neutrophil function by up-regulating both CD11b expression and ROI activity, either alone or in response to LPS. A recent randomized, controlled trial that compared G-CSF and GM-CSF in neonates found that absolute neutrophil count was significantly increased in the G-CSF group above placebo or GM-CSF therapy (41). Therefore, balancing the optimal bactericidal activity of the neutrophil with its potential for tissue damage is essential in the adjunctive use of CSFs in neonatal sepsis. G-CSF had the greatest antiapoptotic effect on neonatal neutrophils, and GMCSF has the greatest effect on function. However, neonates who were at high risk for sepsis were unresponsive to the antiapoptotic effects of G-CSF. This work indicates the need for further research into this area to evolve treatment regimens with carefully titrated doses of CSFs, possibly with both G-CSF and GM-CSF in combination. Optimal timing of administration is crucial to maximize the beneficial aspects of these cytokines, as some neonates may already have high circulating levels so that until these wane, further doses may not be warranted. Understanding the role of the neutrophil in the inappropriately deficient response to sepsis has important implications in the treatment of the infected neonate. Improving neonatal responses to infection may require alternative methods to those used in adult disease to optimize inflammatory responses to infection.

Acknowledgments. We thank all of the parents and laboratory and hospital staff who donated blood samples to this project. We are indebted to Dr. Catherine Moss, Conway Institute, University College Dublin, for technical support with the real-time PCR data. Many thanks also to MaryAnn
O’Riordan, Rainbow Babies and Children's Hospital (Cleveland, $\mathrm{OH}$ ) for statistical support.

\section{REFERENCES}

1. Remington JS, Klein JO 1995 Current concepts of infections of the fetus and newborn infant. In: Remington JS, Klein JO (eds) Infectious Diseases of the Fetus and Newborn Infants. WB Saunders, Philadelphia, pp 1-19

2. Christensen RD, Rothstein G 1980 Exhaustion of mature marrow neutrophils in neonates with sepsis. J Pediatr 96:316-318

3. Weinstein RA 2001 Controlling antimicrobial resistance in hospitals: infection control and use of antibiotics. Emerg Infect Dis 7:188-192

4. Inano H, Kameyama S, Yasui S, Nagai A 1998 Granulocyte colony-stimulating factor induces neutrophil sequestration in rabbit lungs. Am J Respir Cell Mol Biol 19:167174

5. Bernstein HM, Pollock BH, Calhoun DA, Christensen RD 2001 Administration of recombinant granulocyte colony-stimulating factor to neonates with septicemia: a meta-analysis. J Pediatr 138:917-920

6. Carr R, Modi N, Dore C 2003 G-CSF and GM-CSF for treating or preventing neonatal infections. Cochrane Database Syst Rev 3:CD003066

7. Kocherlakota P, La Gamma EF 1998 Preliminary report: rhG-CSF may reduce the incidence of neonatal sepsis in prolonged preeclampsia-associated neutropenia. Pediatrics 102:1107-1111

8. Carr R, Modi N, Dore CJ, El-Rifai R, Lindo D 1999 A randomized, controlled trial of prophylactic granulocyte-macrophage colony-stimulating factor in human newborns less than 32 weeks gestation. Pediatrics 103:796-802

9. Cairo MS, Agosti J, Ellis R, Laver JJ, Puppala B, deLemos R, Givner L, Nesin M, Wheeler JG, Seth T, van de Ven C, Fanaroff A 1999 A randomized, double-blind, placebo-controlled trial of prophylactic recombinant human granulocyte-macrophage colony-stimulating factor to reduce nosocomial infections in very low birth weight neonates. J Pediatr 134:64-70

10. Stephens DP, Fisher DA, Currie BJ 2002 An audit of the use of granulocyte colony-stimulating factor in septic shock. Intern Med J 32:143-148

11. Azoulay E, Attalah H, Yang K, Jouault H, Schlemmer B, Brun-Buisson C, Brochard L, Harf A, Delclaux C 2002 Exacerbation by granulocyte colony-stimulating factor of prior acute lung injury: implication of neutrophils. Crit Care Med 30:2115-2122

12. Bozinovski S, Jones JE, Vlahos R, Hamilton JA, Anderson GP 2002 Granulocyte/ macrophage-colony-stimulating factor (GM-CSF) regulates lung innate immunity to lipopolysaccharide through Akt/Erk activation of NF $\kappa$ and AP-1 in vivo. J Biol Chem 277:42808-42814

13. Jiminez MF, Watson RW, Parodo J, Evans D, Foster D, Steinburg M, Rotstein OD, Marshall JC 1997 Dysregulated expression of neutrophil apoptosis in the systemic inflammatory response syndrome. Arch Surg 132:1263-1269

14. Benitz WE, Han MY, Madan A, Ramachandra P 1998 Serial serum C-reactive protein levels in the diagnosis of neonatal infection. Pediatrics 102:E41

15. Osmanagaoglu MA, Unal S, Bozkaya H 2005 Chorioamnionitis risk and neonatal outcome in preterm premature rupture of membranes. Arch Gynecol Obstet 271:33-39

16. Watson RW, O’Neill A, Brannigen AE, Coffey R, Marshall JC, Brady HR, Fitzpatrick JM 1999 Regulation of Fas antibody induced neutrophil apoptosis is both caspase and mitochondrial dependent. FEBS Lett 453:67-71

17. Li Y, Huang TT, Carlson EJ, Melov S, Ursell PC, Olson JL, Noble LJ, Yoshimura MP, Berger C, Chan PH 1995 Dilated cardiomyopathy and neonatal lethality in mutant mice lacking manganese superoxide dismutase. Nat Genet 11:376-381

18. Smith JA, Weidemann MJ 1993 Further characterization of the neutrophil oxidative burst by flow cytometry. J Immunol Methods 162:261-268

19. Kobayashi S, Yamashita K, Takeoka T, Ohtsuki T, Suzuki Y, Takahashi R, Yamamoto K, Kaufmann SH, Uchiyama T, Sasada M, Takahashi A 2002 Calpainmediated $\mathrm{X}$-linked inhibitor of apoptosis degradation in neutrophil apoptosis and its impairment in chronic neutrophilic leukemia. J Biol Chem 277:33968-33977

20. O'Neill AJ, Doyle BT, Molloy E, Watson C, Phelan D, Greenan MC, Fitzpatrick JM, Watson RW 2004 Gene expression profile of inflammatory neutrophils: alterations in the inhibitors of apoptosis proteins during spontaneous and delayed apoptosis. Shock 21:512-518

21. Maianski NA, Mul FP, van Buul JD, Roos D, Kuijpers TW 2002 Granulocyte colony-stimulating factor inhibits the mitochondria-dependent activation of caspase-3 in neutrophils. Blood 99:672-679

22. Hasegawa T, Suzuki K, Sakamoto C, Ohta K, Nishiki S, Hino M, Tatsumi N, Kitagawa S 2003 Expression of the inhibitor of apoptosis (IAP) family members in human neutrophils: up-regulation of cIAP2 by granulocyte colony-stimulating factor and overexpression of cIAP2 in chronic neutrophilic leukemia. Blood 101:1164-1171

23. Molloy EJ, O'Neill AJ, Grantham JJ, Sheridan-Pereira M, Fitzpatrick JM, Webb DW, Watson RW 2004 Labor promotes neonatal neutrophil survival and lipopolysaccharide responsiveness. Pediatr Res 56:99-103

24. Murphy BM, O’Neill AJ, Adrain C, Watson RW, Martin SJ 2003 The apoptosome pathway to caspase activation in primary human neutrophils exhibits dramatically reduced requirements for cytochrome C. J Exp Med 197:625-632 
25. Molloy EJ, O’Neill AJ, Grantham JJ, Sheridan-Pereira M, Fitzpatrick JM, Webb DW, Watson RW 2003 Sex-specific alterations in neutrophil apoptosis: the role of estradiol and progesterone. Blood 102:2653-2659

26. Uguz A, Coskun M, Yuzbey S, Kizilors A, Karadogan I, Gura A, Yoldas B, Oygur N, Yegin O 2002 Apoptosis of cord blood neutrophils and their response to colonystimulating factors. Am J Perinatol 19:427-434

27. Nupponen I, Andersson S, Jarvenpaa AL, Kautiainen H, Repo H 2001 Neutrophil CD11b expression and circulating interleukin- 8 as diagnostic markers for early-onset neonatal sepsis. Pediatrics 108:E12

28. Christensen RD, Rothstein G 1980 Exhaustion of mature marrow neutrophils in neonates with sepsis. J Pediatr 96:316-318

29. Wolach B, Gavrieli R, Pomeranz A 2000 Effect of granulocyte and granulocyte macrophage colony stimulating factors (G-CSF and GM-CSF) on neonatal neutrophi functions. Pediatr Res 48:369-373

30. Ohls RK, Bellis YM, Dupree JC, Sklar LC 2001 Effects of granulocyte colonystimulating factor on neutrophil adhesive molecules in neonates. J Pediatr Hematol Oncol 23:506-510

31. Jaswon MS, Jones HM, Linch DC 1994 The effects of recombinant human granulocyte-macrophage colony stimulating factor on the neutrophil respiratory burst in the term and preterm infant when studied in whole blood. Pediatr Res 36:623-627

32. Droussou-Agakidou V, Kanakoudi-Tsakalidou F, Sarafidis K, Tarparkou A, Tzimouli V, Tsandali H, Kremenopoulos G 1998 Administration of recombinant human granulocyte-colony stimulating factor to septic neonates induces neutrophilia and enhances the neutrophil respiratory burst and $\beta 2$ integrin expression. Results of randomised controlled trial. Eur J Pediatr 157:583-588

33. Ahmad M, Fleit HB, Golightly MG, La Gamma EF 2004 In vivo effect of recombinant human granulocyte colony-stimulating factor on phagocytic function and oxidative burst activity in septic neutropenic neonates. Biol Neonate 86:48-54
34. Lejeune M, Cantinieaux B, Harag S, Ferster A, Devalck C, Sariban E 1999 Defective functional activity and accelerated apoptosis in neutrophils from children with cancer are differentially corrected by granulocyte and granulocyte-macrophage colony stimulating factors in vitro. Br J Haematol 106:756-761

35. Gessler P, Neu S, Nebe T, Speer CP 1999 Granulocyte colony-stimulating factor receptor expression on neutrophils of term and preterm neonates with and without signs of infection. Eur J Pediatr 158:497-500

36. Cairo MS, Suen Y, Knoppel E, van de Ven C, Nguyen A, Sender L 1991 Decreased stimulated GM-CSF production and GM-CSF gene expression but normal numbers of GM-CSF receptors in human term newborns compared with adults. Pediatr Res 30:362-367

37. Shimada M, Minato M, Takada M, Takahashi S, Harada K 1996 Plasma concentration of granulocyte-colony-stimulating factor in neonates. Acta Paediatr $85: 351-355$

38. Kantar M, Kultursay N, Kutukculer N, Akisu M, Cetingul N, Caglayan S 2000 Plasma concentrations of granulocyte-macrophage colony-stimulating factor and interleukin-6 in septic and healthy preterms. Eur J Pediatr 159:156-157

39. Tehranchi R, Fadeel B, Forsblom AM, Christensson B, Samuelsson J, Zhivotovsky B, Hellstrom-Lindberg E 2003 Granulocyte colony-stimulating factor inhibits spontaneous cytochrome $c$ release and mitochondria-dependent apoptosis of myelodysplastic syndrome hematopoietic progenitors. Blood 101:1080-1086

40. Maianski NA, Roos D, Kuijpers TW 2004 Bid truncation, bid/bax targeting to the mitochondria, and caspase activation associated with neutrophil apoptosis are inhibited by granulocyte colony-stimulating factor. J Immunol 172:7024-30

41. Ahmad A, Laborada G, Bussel J, Nesin M 2002 Comparison of recombinant granulocyte colony-stimulating factor, recombinant human granulocyte-macrophage colony-stimulating factor and placebo for treatment of septic preterm infants. Pediatr Infect Dis J 21:1061-1065 